This item was submitted to Loughborough's Research Repository by the author.

Items in Figshare are protected by copyright, with all rights reserved, unless otherwise indicated.

\title{
Geographic variation in Sundew (Drosera ) leaf colour: plant-plant interactions counteract expected effects of abiotic factors
}

\section{PLEASE CITE THE PUBLISHED VERSION}

https://doi.org/10.1111/jbi.13141

\section{PUBLISHER}

(c) Wiley

\section{VERSION}

AM (Accepted Manuscript)

\section{PUBLISHER STATEMENT}

This work is made available according to the conditions of the Creative Commons Attribution-NonCommercialNoDerivatives 4.0 International (CC BY-NC-ND 4.0) licence. Full details of this licence are available at: https://creativecommons.org/licenses/by-nc-nd/4.0/

\section{LICENCE}

CC BY-NC-ND 4.0

\section{REPOSITORY RECORD}

Millett, Jonathan, G.W. Foot, Julia C. Thompson, and B.M. Svensson. 2017. "Geographic Variation in Sundew (drosera ) Leaf Colour: Plant-plant Interactions Counteract Expected Effects of Abiotic Factors". Loughborough University. https://hdl.handle.net/2134/28154. 
1 Article type: original article

2 Geographic variation in Sundew (Drosera) leaf colour: plant-plant interactions 3 counteract expected effects of abiotic factors.

$4 \quad$ Millett, $\mathrm{J}^{1 *}$, Foot, $\mathrm{GW}^{1,3}$, Thompson, $\mathrm{JC}^{1}$, Svensson, $\mathrm{BM}^{2}$

$5{ }^{1}$ Centre for Hydrological and Ecosystem Sciences, Department of Geography, 6 Loughborough University, Loughborough, LE11 3TU, UK.

$7 \quad{ }^{2}$ Plant Ecology and Evolution, Department of Ecology and Genetics, EBC, Uppsala

8 University, Norbyvägen 18 D, SE-752 36, Uppsala, Sweden.

$9{ }^{3}$ Department of Plant Sciences, University of Cambridge, Downing Street, 10 Cambridge, CB2 3EA, UK.

11 Corresponding author: Jonathan Millett, Centre for Hydrological and Ecosystem 12 Sciences, Department of Geography, Loughborough University, Loughborough, 13 LE11 3TU, UK. j.millett@lboro.ac.uk

14 Running head: Geographic variation in Drosera rotundifolia leaf colour.

15 Number of words: 6586 


\section{Abstract}

Aim

To identify geographical patterns in leaf colour of Roundleaved Sundew (Drosera rotundifolia) growing on ombrotrophic (rain fed) bogs across Europe and establish the controls over these patterns.

\section{Location}

North-west Europe.

Taxon

Angiosperms, Drosera rotundifolia

Methods

We measured leaf colour of $D$. rotundifolia plants growing on 24 ombrotrophic bogs across north-west Europe covering 26.4 degrees of longitude, and 21.1 degrees of latitude. We measured the height and cover of co-occurring vascular plant vegetation and the amount of incident light intercepted by the vegetation canopy. We determined the role of abiotic variables in controlling the patterns found. In a separate experimental study, we manipulated plant-plant interactions with $D$. rotundifolia by removing above-ground vascular plant vegetation and monitoring leaf colour over a single summer.

\section{Results}

Drosera rotundifolia leaf colour varied between bogs. Leaves were redder in northern latitudes and eastern longitudes, and in sites/plots with lower canopy influence, lower nutrient deposition, and a more continental climate. Canopy influence was greater on sites in southern latitudes, eastern longitudes, and with higher nutrient deposition, longer growing seasons and a more maritime climate. Nutrient deposition was higher at more southerly latitudes, eastern sites had a more continental climate, southern and western sites had warmer and longer growing seasons. In the in-situ experiment leaves became more red when canopy light transmission was increased by removing vegetation, but not when shade net was subsequently added to reduce light transmission.

\section{Main conclusion}

Geographic variation in Drosera rotundifolia leaf colour is strongly affected by its light environment, mediated by plant-plant interactions, but leaf colour is also affected by other abiotic factors. The relative importance of biotic and abiotic factors in determining geographic patterns in traits, and also species responses to environmental change, might depend on the growth form and competitive ability of a species. 
53 Keywords: anthocyanin, Drosera, environmental gradients, leaf colour, light, 54 nutrients, plant-plant interactions, sundew, trait variation

55 


\section{Introduction}

A major goal in ecology is to understand how biotic and abiotic processes influence species distributions, and how individuals respond to these factors. Plant species with broad geographic distributions experience a wide range of biotic and abiotic conditions and plant traits can vary in response. Understanding the patterns and causes of this within-species geographic variability in traits can, therefore, provide insight into the links between plant function, biotic and abiotic interactions (Gaston et al., 2008). It can also help us to understand the impacts on ecosystems of anthropogenic drivers such as altered precipitation patterns and increased temperature (Millien et al., 2006; Zeuss et al. , 2014), and deposition of atmospheric pollutants such as nitrogen and sulphur (Ellison \& Gotelli, 2002; Millett et al., 2015). For example, phenotypic variability along latitudinal gradients reflects the combination of adaptive and plastic effects, which can inform understanding of the effects of warming on plant distributions (De Frenne et al., 2013); latitudinal gradients in nitrogen deposition have also been used to better understand species responses to atmospheric nitrogen deposition (e.g., Millett et al., 2012)

Biotic interactions vary geographically-it is predicted that the intensity of biotic interactions will be greater closer to the equator (Schemske et al., 2009)—and play an important role in maintaining biodiversity (Brooker, 2006). Considerable uncertainty remains, however, about the existence and shape of these geographical patterns (Moles et al., 2011; Ollerton et al., 2011; Poore et al., 2012; Dalrymple et al. , 2015), and many different patterns might actually exist. Geographic patterns of plant-plant interactions might be particularly important because of their key role in structuring plant communities. These interactions are predicted by the stressgradient hypothesis (SGH; Connell, 1983) to be more intense in more productive environments. This has important implications for plant community responses to global environmental change because many of the key drivers, such as eutrophication and warming, will increase productivity in many systems (Brooker, 2006). Experimental evidence from altitudinal and latitudinal gradients supports the SGH (Callaway et al., 2002; Kikvidze et al., 2011). These studies, however, are limited in number and are manipulative so might suffer from artefacts of the experimental approach. Another approach would be to investigate variability in plant traits relating to plant-plant interactions along these productivity gradients, but this relies on the identification of appropriate traits.

Carnivorous plants trap and digest animal prey, assimilating the nutrients into their tissues. Drosera rotundifolia L. is a small carnivorous herb, which occupies ombrotrophic (rain fed) bogs and catches prey with sticky mucilage secreted on the end of leaf trichomes (tentacles). Like many carnivorous plants the leaves of $D$. rotundifolia have a distinctive red colouration, due to the presence of anthocyanins (Egan \& der Kooy 2013). This red colour was thought to serve a prey attraction function (Lloyd, 1942; Ichiishi et al., 1999), but experimental studies have shown this not to be the case (Foot et al., 2014). Alternative hypotheses for the functional role of 
leaf reddening are as a protection against excess light and UV-B radiation, herbivory defence or osmotic adjustment. Aboveground interactions with other plants might be crucial to the ecology of carnivorous plants (Ellison et al., 2003) because the costs of carnivory mean that a net benefit should only occur in high-light environments (Givnish et al., 1984). Aboveground interactions with shrubs might be particularly important for the ecology of $D$. rotundifolia because of its rosette form, with leaves close to the bog surface, meaning it is usually subordinate in the plant canopy.

We used both a correlative and experimental approach to explore in ombrotrophic (rain fed) bogs the relationship between latitude, vegetation structure and leaf colour of the carnivorous plant Drosera rotundifolia. The aim of the correlative study was to identify geographic patterns in $D$. rotundifolia leaf colour, vascular plant cover and canopy characteristics; the aim of the experimental study was to determine whether the red leaf pigmentation of $D$. rotundifolia leaves is light sensitive and influenced by aboveground plant-plant interactions. We hypothesised that 1. the red colour of $D$. rotundifolia leaves is light responsive; 2 . the intensity of above-ground interactions between $D$. rotundifolia and other vegetation decreases towards the poles, due to decreased productivity; and 3 . these changing interactions are indicated by a change in $D$. rotundifolia leaf colour, with leaves becoming redder due to increased light transmission through the vegetation canopy. An alternative hypothesis is that leaves will become less red towards the poles because, in the absence of plant-plant interactions, a strong latitudinal gradient of solar radiation (due to differences in the solar angle) reduces the requirement for photoprotective adaptation at higher latitudes. This alternative hypothesis has been demonstrated for photoprotective metabolites in other plant species (Willis et al., 2011; Koski \& Ashman, 2015).

\section{Materials and Methods}

\section{Correlative study}

For the correlative study 25 ombrotrophic bogs were chosen across western and northern Europe covering 26.4 degrees of longitude $\left(-7.638-18.810^{\circ} \mathrm{E}\right)$, and 21.1 degrees of latitude $\left(47.239-68.356{ }^{\circ} \mathrm{N}\right.$ ) (site details are in Appendix S1 in Supporting Information, locations are in Fig. 1). To reduce variability due to habitat differences we only measured plants growing on Sphagnum spp. hummocks. At each site, hummocks (c. $4 \mathrm{~m}^{2}$ ) were selected on the intact ombrotrophic parts of the bog. The number of hummocks varied depending on the size of the bog and available time for sampling (median $=6$, range $4-10$ ). To reduce the possibility of seasonal differences, sampling took place in a four-week period from late July early August; because of the work involved, we sampled bogs over three years (2011 - 2013) to keep sampling within this time window.

On each hummock we recorded the percent cover and height of vascular plants. Cover was based on the average of independent estimates of at least two people; height was based on the average of ten randomly located measurements. To 
determine the impact of the vegetation canopy on the light environment at the bog surface we measured photosynthetically active radiation (PAR) above the plant canopy and on the bog surface at five points using a PAR quantum sensor (SKP 215, Skye Instruments, Powys, UK). PAR was always measured between 10:00 and 15:00. One fully formed leaf was removed from each of ten $D$. rotundifolia plants per plot and kept chilled at below $10^{\circ} \mathrm{C}$ but above $0^{\circ} \mathrm{C}$ before colour analysis. As soon as possible, and within 4 hours, we measured the spectral reflectance of the leaves within the wavelength range $400-800 \mathrm{~nm}$ using a VIS-NIR spectrometer (USB4000, Ocean Optics Inc.). The probe was held $15 \mathrm{~mm}$ from the leaf giving a measurement area of approximately $35 \mathrm{~mm}^{2}$. Drosera rotundifolia leaf spectrometry was carried out for all sites where $D$. rotundifolia was present $(n=24)$ but vegetation characteristics only for a sub-set of sites ( $n=18$ for vegetation height, cover and light interception).

Canopy light transmission was calculated as PAR at the bog surface as a proportion of above-canopy PAR. This removed the impact of differences in incident light due to meteorological conditions or site differences. Canopy photographs were analysed using the software integrated into the $\mathrm{Cl}-110$ system. Sky and vegetation were differentiated in the photographs using a threshold determined manually, based on a visual assessment. From this the canopy transmission coefficient was calculated, this is the proportion of the photograph that is sky (rather than vegetation). We carried out the initial data analyses with and without these canopy photograph data. The results of both approaches were qualitatively identical; because of this, and because these canopy photography data were only available for a smaller sub-set of sites, we excluded these data from the analyses. At all sites, no shading of plots was present due to rocks or trees. Leaf reflectance data were used to calculate leaf colour using SPECTRASUITE 2.0 (Ocean Optics 2010). We determined the colour of the leaves using multiple colour measures: $\mathrm{a}^{*}$ (a measure of red - green colour) in CIE $1976\left(L^{*} a^{*} b^{\star}\right)$ colour space (CIELAB), 'dominant wavelength' (the dominant wavelength of the colour in CIE 1976 colourspace, removing differences in saturation or intensity), mean red (600-699 nm), green (500-599 nm) reflectance and the ratio of red:green reflectance. The choice of measures is non-exhaustive and was driven by a wish to define the redness or greenness of the leaves, balancing the number of measures used against simplicity. Further details are in appendix S2 in Supporting Information.

\section{Experimental study}

The experimental study was carried out in 2012 at Thorne Moor, part of the Humberhead Peatlands National Nature Reserve, in the UK (Lat: $53.6385^{\circ}$, Long: $\left.0.9009^{\circ}\right)$. We carried out this experiment within a single trench in the peat, c. $20 \mathrm{x}$ $100 \mathrm{~m}$. The trench was originally formed by hand cutting of the peat in the $19^{\text {th }}$. century and has since revegetated with Sphagnum spp. (with a developing hummock hollow topography), small shrubs and $D$. rotundifolia, such that the surface of the Sphagnum is now level with the surface of surrounding uncut baulks. We chose five 
plots, each on a different Sphagnum hummock. At each hummock, we established three $0.5 \times 0.5 \mathrm{~m}$ sub-plots. Each sub-plot was randomly allocated to one of three treatments: 1. 'natural' - vegetation left intact; 2. 'removed' - all aboveground vegetation, except $D$. rotundifolia, removed; and 3. 'removed+shaded' - all aboveground vegetation, except $D$. rotundifolia, removed and a $0.5 \times 0.5 \mathrm{~m}$ square wooden frame covered in neutral shade cloth (to give a reduction in light intensity of approximately 50\%) placed over the plot at a height of approximately $20 \mathrm{~cm}$. The removed+shaded treatment was included to determine the extent to which changes due to vegetation removal (removed) could be attributed to impacts of vegetation on the aboveground light environment.

We applied the treatments on $6^{\text {th }}$ June 2012 . The light environment on the Sphagnum surface was measured by measuring PAR above the plant canopy/shade frame (or at a height of c. $30 \mathrm{~cm}$ for removed plots) and at the Sphagnum surface. Canopy light transmission was calculated as for the correlative study. On $15^{\text {th }}$ August one fully formed leaf was removed from each of ten $D$. rotundifolia plants in each sub-plot. Spectral reflectance of each leaf was determined using the approach detailed for the correlative study.

\section{Environmental variables data sets}

We compiled a set of abiotic variables for each site, chosen to reflect the potential to impact on vegetation or leaf colour characteristics. These variables covered meteorological, nutrient deposition and UV radiation data. We used UV-B dose as an indicator of likely radiative dose because in plants $U V$ is responsible for approximately one third of photodamage (Takahashi \& Badger, 2011). UV-B exposure data for each plot were obtained from gIUV (Beckmann et al., 2014). This dataset provides satellite-derived estimates of global surface UV-B dose at a 15 arcminute resolution. We used the UVB5 layer, which provides the sum of monthly mean (2004-2013) UV-B during the highest quarter. Annual atmospheric N (total N, $\mathrm{NO}_{3}, \mathrm{NH}_{4}$ and the ratio of $\mathrm{NO}_{3}: \mathrm{NH}_{4}$ ) and total $\mathrm{S}$ deposition was modelled using a higher resolution national model for the UK (Smith et al., 2000; NEGTAP, 2001) and for non-UK sites using the lower resolution European Monitoring and Evaluation Program (EMEP)-based Integrated Deposition Model (IDEM) (Pieterse et al., 2007). Meteorological data comprised the following variables: mean annual (July - June) temperature, minimum January and maximum July temperature, temperature variability (CV for temperature in Fahrenheit), growing degree days (base 5), and mean annual precipitation for the previous five years for each site (with a 0.25 degree latitude-longitude resolution). The variables were calculated using an interpolated data set from E-OBS (Haylock et al., 2008) accessed through the KNMI climate explorer (KNMI, 2013). For these variables, the mean values for the fiveyears prior to plot measurements were used to represent the likely time-scale of impacts on $D$. rotundifolia, which has an average life span of six years, while balancing the likely larger influence of more recent abiotic conditions. 
Data were analysed in IBM STATISTICS 22.0 (IBM Corp., 2013). Some data reduction was carried out before analysis. Measurements within each plot were averaged to give a mean per plot. These data were used to compare the relationship between canopy characteristics and leaf colour. For all other analyses comparisons were required at the site level ( $n=14-26$ sites), so were based on means at each site (i.e. means of plot means, $n=10$ plants per plot and $5-10$ plots per site). There were correlations among abiotic variables, so we performed principal components analysis (PCA) with Varimax rotation on these data. We also used PCA to reduce the five leaf colour measurements to a single index of colour and to reduce the canopy characteristics measures to a single index of canopy influence. These last two PCAs were carried out separately for the site-level and plot-level data analysis.

To determine the relationships between variables we used either simple linear regression (for single independent variables) or, where there were multiple independent variables, stepwise ordinary least squares (OLS) regression with forward and backward inclusion, an inclusion cut-off at $P=0.05$ and an exclusion cut-off at $P=0.1$. We first determined any systematic geographic variability in the data by using the PCA axes for the environmental, canopy and colour characteristics as dependent variables and latitude and longitude as independent variables (sites west of $0^{\circ}$ were coded as negative). We also separately analysed geographical variability in vegetation height, because plant height has previously been shown to vary systematically with latitude (Moles et al., 2009). To do this we used the 'curve estimation' module in IBM Statistics. Appropriateness of the fitted model was assessed by inspecting plots of residuals and the model with the highest $r^{2}$ value was chosen.

Next, we used the three environmental PCA axes as independent variables and the indices (i.e., PCA axis score) of vegetation influence and D. rotundifolia colour characteristics as dependent variables to determine the relationship between the abiotic environment and biotic variables. We also analysed the relationship between UV-B and leaf colour separately because UV-B has been previously implicated in differences in plant colour along latitudinal gradients (Koski \& Ashman, 2015).

To determine the relationship between canopy characteristics and leaf colour, we used a linear mixed model on plot-level data. We used a two-level model to account for relationships between and within sites. We used plot as a random effect, nested within site, and canopy influence as a fixed effect. We compared four models: 1 . null single-level model, 2. null multi-level model, 3. random intercepts model and 4. random slopes and intercepts model. Differences in the appropriateness of each model was tested with a 'log likelihood ratio test', comparing with the previous, less complex model. 
For the experimental study the impact of the three was tested by comparing differences in the ground-level light environment after treatments were established and the colour (CIE Lab $\left.a^{\star}\right)$ of $D$. rotundifolia leaves at the end of the experiment. We did this tested using a randomised block design ANOVA with hummocks as blocks and subplots as treatments within blocks. Differences between the three treatments were tested using post-hoc comparisons (Fisher's LSD).

\section{Results}

\section{PCA results}

For the bioclimatic variables, the first three PCA axes explained total of $85.5 \%$ of variation (29.5, 29.3 and $26.7 \%$ for axes 1,2 \& 3 respectively), and were successful in differentiating between the different groups of environmental variables (Table 1). Axis 1 reflected nutrient deposition differences among the sites, with high scores on this axis representing sites with a high $\mathrm{N}$ and $\mathrm{S}$ deposition load (higher total $\mathrm{N}$, total $\mathrm{S}, \mathrm{NO}_{3}$ and $\mathrm{NH}_{4}$ deposition). Axis 2 reflected differences among sites in summer meteorological conditions, sites with high scores on this axis had warmer summers and a longer growing season (higher mean summer temperature, high maximum July temperature and high GDD). Axis 3 reflected the continentality of the climate, sites with high scores on this axis had a more maritime, less continental climate (high January minimum temperature, mean annual temperature, and precipitation, and low monthly temperature variance).

We also used PCA to reduce multiple indices of leaf colour and multiple measures of canopy influence to single principle components. For canopy influence and leaf colour, only a single PCA axis was extracted. For canopy influence the first PCA axis explained $79.8 \%$ of between-site variability (Table 2 ). Sites with high scores on this axis had high vegetation cover, tall vegetation and high interception of incident PAR. The PCA axis for leaf colour explained $85 \%$ of the variability and differentiated on the basis of how red or green the leaves were (Table 2). Sites in which plants had redder leaves had high values on this axis, which indicated high CIE LAB $a^{*}$, high values for the dominant wavelength reflected, red reflectance and the ratio of red:green reflectance, and low values for green reflectance.

\section{Patterns}

There are some clear geographic patterns in the three data components (leaf colour, vegetation influence, abiotic variables), and some clear patterns of variation between these different components (full analysis results are in Appendix S3 in Supporting Information). The multiple regression analysis showed that geographic variability in $D$. rotundifolia leaf colour was best explained by a linear regression model which included both latitude and longitude. This explained $65.7 \%$ of between-site variability in leaf colour (Table 3). Canopy influence and vegetation height varied with only latitude, which explained $81.6 \%$ and $84.7 \%$ of variability respectively. Abiotic PCA axis 1 (nutrient deposition) varied with only latitude; abiotic axis 2 (summer growing 
conditions) varied with both latitude and longitude; abiotic axis 3 (continentality) varied with only longitude. (See appendix S3.)

When considering only abiotic variables, variability in canopy influence and vegetation height was best explained by a model which included abiotic PCA axes 3 , 1 and 2 (continentality, nutrient deposition and summer climate respectively). This model explained $86.5 \%$ of the variability in canopy influence and $89.5 \%$ of the variability in vegetation height (Table 3 ). However, a model including only PCA axis 1 and 3 best explained variability in leaf colour, explaining $72.1 \%$ of variability in leaf colour. There was no significant relationship between summer temperature/growing degree days and leaf colour. (See appendix S3.)

Canopy influence (vegetation height, cover and light interception) was higher in more northerly and easterly sites (Fig. 2 a \& b), though variation with longitude was not statistically significant. Drosera rotundifolia leaves were redder in more northerly and easterly sites (Fig. 2c \& d). More easterly sites experienced a more continental climate (lower precipitation, lower winter temperature and higher climate variability (Fig. 3a) and higher summer temperatures/longer growing seasons (Fig. 3b). More northerly sites received lower levels of nutrient deposition (Fig. 3c) and lower summer temperatures/longer growing seasons (Fig. 3d).

Canopy influence was greater on sites with a more maritime climate than on sites with a more continental climate (Fig. 4a). Drosera rotundifolia on sites with a more continental climate had redder leaves than those with a more maritime climate (Fig. 4b). Sites with higher nutrient deposition had higher canopy influence than those with lower nutrient deposition (Fig. 4c). Drosera rotundifolia in these higher nutrient deposition sites had greener leaves than those in the lower nutrient deposition sites (Fig. 4d). Sites with high summer temperatures and longer growing seasons had greater canopy influence and taller vegetation (Fig. 4e).

For the relationship between canopy influence and leaf colour, the model which included both random intercept and slope was the highest ranked based on the -2log likelihood score (comparison is shown in appendix S4 in Supporting Information). This indicates differences between sites in both the relationship between canopy influence and leaf colour, and in the expected leaf-colour at average canopy influence (Fig. 5, appendix S5 in Supporting Information). For this model, overall there was a statistically significant relationship between canopy influence and leaf colour (LMM: d.f. $=19.272, \mathrm{t}=-3.778, P=0.001$ ); leaves were less red when canopy influence was higher. The extent of this relationship varied between sites. A strong negative correlation existed between the intercept and slope of the fitted lines (Pearson's Correlation Coefficient: $-0.85, P<0.001$ ); this indicates that, for sites with a lower intercept (i.e. indicating greener leaves when canopy influence was at the mean of all plots), the slope of the relationship between canopy influence and leaf colour was less steep (i.e. leaf colour varied less with canopy influence). 
We used UV-B radiation dose as an indicator of the potential for incident radiation to influence leaf colour. The above-canopy UV-B dose received by the sites was strongly dependent on latitude, decreasing towards the poles (linear regression: $F_{1}$, ${ }_{23}=46.18, r^{2}=0.67, P<0.001$ ), but the leaves of $D$. rotundifolia growing at sites which received a higher UV-B dose had greener leaves than those at sites with a lower UV-B dose (Linear regression: $F_{1,23}=10.364, P=0.004, r^{2}=0.311$ ). These were also the sites with higher canopy influence scores (Pearson correlation coefficient for UV-B vs canopy influence $=0.613, P=0.005)$.

In our in-situ experimental study $D$. rotundifolia leaf colour changed as a result of interactions with co-occurring plants, due to impacts on the light environment. We doubled light transmission through the canopy (Fig. 6 , ANOVA: $F_{2,8}=48.94, P$ $<0.001$ ) by removing all aboveground vegetation. After ten weeks, the leaves of $D$. rotundifolia plants in these vegetation removal plots were redder than the leaves of plants in control plots (Fig. 6, ANOVA: $\left.F_{2.8}=11.93, P=0.004\right)$. We also controlled for possible impacts of plant removal independent of their shading effect by adding shade cloth to vegetation removal plots - intercepting approximately the same amount of light as the plant canopy. In these shaded plots, the change in $D$. rotundifolia leaf colour was not present (Fig. 6).

\section{Discussion}

We demonstrate systematic geographic variability in plant leaf colour for the first time. Drosera rotundifolia leaves were redder in more northerly and easterly sites. Our results provide evidence that this pattern may be controlled to some extent by geographic variability in plant-plant interactions, which are themselves influenced by variation in climate and nutrient deposition. While geographic variation in animal pigmentation has been well-studied (Gloger, 1883; Jablonski \& Chaplin, 2000; Lai et al., 2008; Alho et al., 2010; Tuomaala et al., 2012; Zeuss et al., 2014), geographic variability in plant colour is poorly understood. Plants are, however, subject to different evolutionary and environmental constraints to animals (Bradshaw, 1972; Huey et al., 2002). For example, the sessile nature of plants might result in morepronounced stress resistance mechanisms (Huey et al., 2002) such as pigmentation. Plants might also be influenced by biotic interactions to a greater extent. Moles et al. (2011) showed that plant height across ecosystems decreased as a function of latitude. We found the same pattern within a single ecosystem, ombrotrophic bogs. We also found that this, in association with an associated decrease in vegetation cover, reduced canopy light interception altering the light environment of $D$. rotundifolia plants.

The results of our experimental study show that $D$. rotundifolia leaf colour can be directly influenced by vegetation impacts on the light environment. Leaf colour was light sensitive, changing from green to red in response to short-term increases in light intensity due to a reduction in aboveground plant-plant interactions. Increased leaf redness of $D$. rotundifolia indicates higher concentrations of anthocyanins (Egan 
\& der Kooy 2013)—-though this was not measured directly. These experimental results suggest that variability in the influence of aboveground vegetation is a plausible explanation for the geographic pattern of leaf colour. This is supported by the clear and strong relationship between canopy measurements and $D$. rotundifolia leaf colour in our correlative study. We suggest that these changes are at least partially responsible for the observed leaf colour changes, and as far as we are aware, this is the first direct, non-manipulative evidence of such a pattern.

The abiotic conditions for plant growth can vary significantly geographically. Within a species, adaptive and plastic responses of plants to these different and variable conditions result in geographic variability in traits. This phenotypic variability can itself have important impacts on ecological dynamics (Bolnick et al. 2011). Our data suggest that biotic interactions might also play a significant role in geographical patterns of plant traits, and can be more important than changes in abiotic conditions-reversing their impact even. Biotic interactions are thought to increase in importance towards the equator (Schemske et al., 2009), and are considered to be one of the key drivers of latitudinal biodiversity gradients (Mittelbach et al., 2007). There is, however, little evidence of broad geographical patterns in plant-plant interactions. Our results suggest that photosensitive plant secondary metabolites might provide a novel way to test for variability in aboveground plant-plant interactions.

Disentangling the correlative patterns in this study was challenging. Leaf-colour, canopy influence and abiotic variables all covaried. Leaf-colour varied with latitude and longitude; canopy influence only varied with latitude. Canopy influence varied in response to all three abiotic PCA axes; leaf colour did not respond to PCA axis 2, which related to growing season temperature. These results might indicate that canopy influence is not the only factor controlling geographic variation in leaf colour in our dataset. For example, the longitudinal gradient in leaf colour might be due to the corresponding impact of increasing continentality of the climate. Leaves were redder in sites which experienced larger extremes of temperature. Low temperatures have been previously suggested to influence anthocyanin synthesis (Close \& Beadle 2003), and this could be the case here. The between-site differences in the relationship between canopy influence and leaf-colour support this. It is clear that further, experimental, studies are required to determine causation.

The adaptive function of $D$. rotundifolia leaf reddening was not tested, but has been implicated in photoprotective and stress response roles in other species (Mendez et al. 1999; Close \& Beadle 2003; Boldt et al. 2014). While anthocyanin synthesis in response to light intensity does not directly demonstrate a photoprotective function per se, we consider it a plausible explanation. Were this the case, the latitudinal gradient in leaf colour is opposite to expected patterns—-photoprotective pigments are predicted to increase towards the equator and higher altitudes, due to the increased intensity of solar radiation. This has been shown to be the case-UV absorbing pigments in Argentina anserina flowers (Koski \& Ashman, 2015) and 
concentrations of the UV-B absorbing compound para-coumaric acid in Pinus sylvestris (Willis et al., 2011), for example, increase towards the equator. Conversely, Åkerström et al., (2010), found that anthocyanin concentrations in the fruit of Bilberry (Vaccinium myrtillus) increased towards the pole in Europe. No clear mechanism for this unexpected pattern has yet been demonstrated, though decreased temperature at very high latitudes has been suggested as a possible mechanism. We also found that red colouration (and likely anthocyanin synthesis) increased towards the pole. The difference between these two groups of species is canopy position. Argentina anserina grows in relatively open habitats, $P$. sylvestris tends to be dominant or co-dominant in forest canopies; the $V$. myrtillus studied by Åkerström et al., (2010) were growing under a forest canopy, and the D. rotundifolia in our study were growing under a shrub canopy. These observations and our study present a potential mechanism for this difference-plant-plant interactions. In plants, UV is responsible for approximately one third of photodamage (Takahashi \& Badger, 2011), so incident UV dose would be expected to be positively correlated with photoprotective metabolites (Willis et al., 2011; Koski \& Ashman, 2015). We found the opposite. We therefore predict that, for plants that are subordinate in the vegetation canopy, geographic variability in plant-plant interactions, especially competition for light, are a more important determinant of the synthesis of photoprotective pigments than variability in above-canopy radiation dose. This is intuitive, but has not been previously suggested.

An alternative and intriguing hypothesis is that leaf redness in Drosera rotundifolia is an anti-herbivory adaptation-either providing crypsis, or as an aposematic warning. There is some evidence for this in other plant species (Manetas 2006). For $D$. rotundifolia in sites with more vegetation cover, the need to deter herbivores might be reduced because the plants will be 'hidden' by the vegetation canopy. In more open areas the plants might be more apparent and so more likely to be seen by herbivores. Foot et al. (2012) found that, in a study of prey capture by D. rotundifolia, fewer insects were attracted to red artificial leaves than to green artificial leaves. This might indicate that insects are deterred by red colouration. This hypothesis warrants further investigation in carnivorous plants.

In conclusion, understanding geographic variability in other traits of this widespread species and their underlying genetic basis would provide a useful model system for understanding how climate change might impact on species distributions. Biotic interactions and local adaptation are poorly represented in species distribution models (Gotelli \& Stanton-Geddes, 2015); we suggest that plant-plant interactions with $D$. rotundifolia vary strongly with latitude and longitude so it might represent a species where current distribution models would be particularly unreliable. It is not unlikely that this is also true for other species. In addition, between-population variability in other traits such as nitrogen nutrition of $D$. rotundifolia has also been demonstrated (Millett et al., 2012, 2015) and might warrant further investigation of the potential for local adaptation. Our data also raise a number of further questions. 
The extent to which geographic variability in leaf colour is a result of adaptive vs plastic variability cannot be determined, though we present evidence that leaf colour can clearly exhibit phenotypic plasticity. Furthermore, it is still not clear why Drosera are red, and more widely, what the adaptive function (if any) is of leaf/trap redness in carnivorous plants. The commonness of leaf redness in carnivorous plants, across unrelated organisms, might provide a useful system for studying the adaptive significance of leaf reddening in plants.

\section{Acknowledgements}

We thank the various landowners and statutory bodies for allowing access to sites for this study. JM was funded by the British Ecological Society, the Botanical Research Fund and Loughborough University, GF was funded by the Engineering and Physical Sciences Research Council, BS was funded by Uppsala University. We thank Fei Mengjie for help with colour analyses and Mark Szegner for help with drawing Fig. 1. The comments of three reviewers were invaluable and their input is gratefully acknowledged.

\section{Appendices}

Appendix S1 Characteristics of study sites.

Appendix S2 Leaf colour measurement methods

Appendix S3 Multiple regression results.

Appendix S4 Linear mixed model results.

Appendix S5 Data used in the study.

\section{References}

Åkerström, A., Jaakola, L., Bång, U. \& Jäderlund, A. (2010) Effects of latitude-related factors and geographical origin on anthocyanin concentrations in fruits of Vaccinium myrtillus L. (Bilberries). Journal of Agricultural and Food Chemistry, 58, 11939-11945.

Alho, J.S., Herczeg, G., Söderman, F., Laurila, A., Jönsson, K.I. \& Merilä, J. (2010) Increasing melanism along a latitudinal gradient in a widespread amphibian: local adaptation, ontogenic or environmental plasticity? BMC Evolutionary Bology, 10, 317.

Beckmann, M., Václavík, T., Manceur, A.M., Šprtová, L., von Wehrden, H., Welk, E. \& Cord, A.F. (2014) glUV: A global UV-B radiation dataset for macroecological studies. Methods in Ecology and Evolution, 5, 372-383.

Boldt, J.K., Meyer, M.H. \& Erwin, J. E. (2014) Foliar Anthocyanins: A Horticultural Review. Horticultural Reviews: Volume 42 (ed. by J. Janick), pp. 209-252. John Wiley \& Sons, Inc., New Jersey. doi: 10.1002/9781118916827.ch04

Bolnick, D.I., Amarasekare, P., Araújo, M.S, Bürger, R., Levine, J.M., Novak, M., Rudolf, V.H.W., Schreiber, S.J., Urban, M.C. \& Vasseur, D.A. (2011) Why 
intraspecific trait variation matters in community ecology. Trends in Ecology and Evolution, 26, 183-192.

Bradshaw, A. (1972) Some evolutionary consequences of being a plant. Evolutionary Biology, 5, 25-47.

Brooker, R.W. (2006) Plant - plant interactions and environmental change. New Phytologist, 171, 271-284.

Callaway, R.M., Brooker, R.W., Choler, P., Kividze, Z., Lortie, C.J., Michalet, R., Paolini, L., Pugnaire, F.I., Newingham, B., Aschehoug, E.T., Armas, C., Kikodze, D. \& Cook, B.J. (2002) Positive interactions among alpine plants increases with stress. Nature, 417, 844-848.

Close, D.C. \& Beadle, C.L. (2003) The ecophysiology of foliar anthocyanin. The Botanical Review, 69, 149-161.

Connell, J. (1983) On the prevalence and relative importance of interspecific competition: evidence from field experiments. American Naturalist, 122, 661696.

Egan, P.A., \& der Kooy, F. (2013) Phytochemistry of the carnivorous sundew genus Drosera (Droseraceae)-future perspectives and ethnopharmacological relevance. Chemistry \& Biodiversity, 10, 1774-1790.

Ellison, A.M., Gotelli, N.J., Brewer, J.S., Cochran-Stafira, D.L., Kneitel, J.M., Miller, T.E., Worley, A.C. \& Zamora, R. (2003) The evolutionary ecology of carnivorous plants. Advances in Ecological Research, 33, 1-74.

Ellison, A.M. \& Gotelli, N.J. (2002) Nitrogen availability alters te expression of carnivory in the northern pitcher plant, Sarracenia purpurea. Proceedings of the National Academy of Sciences, 99, 4409-4412.

Foot, G., Rice, S.P. \& Millett, J. (2014) Red trap colour of the carnivorous plant Drosera rotundifolia does not serve a prey attraction or camouflage function. Biology Letters, 10, 20131024.

De Frenne, P., Graae, B.J., Rodríguez-Sánchez, F., Kolb, A., Chabrerie, O., Decocq, G., De Kort, H., De Schrijver, A., Diekmann, M., Eriksson, O., Gruwez, R., Hermy, M., Lenoir, J., Plue, J., Coomes, D. a. \& Verheyen, K. (2013) Latitudinal gradients as natural laboratories to infer species' responses to temperature. Journal of Ecology, 101, 784-795.

Gaston, K.J., Chown, S.L. \& Evans, K.L. (2008) Ecogeographical rules: elements of a synthesis. Journal of Biogeography, 35, 483-500.

Givnish, T.J., Burkhardt, E.L., Happel, R.E. \& Weintraub, J.D. (1984) Carnivory in the bromeliad Brocchinia reducta, with a cost/benefit model for the general restriction of carnivorous plants to sunny, moist, nutrient-poor habitats. The American Naturalist, 124, 479-497.

Gloger, C. (1883) Das Abandern der Vogel durch Einfluss des Klimas, A. Schulz, Breslau.

Gotelli, N.J. \& Stanton-Geddes, J. (2015) Climate change, genetic markers and species distribution modelling. Journal of Biogeography, 42, 1577-1585. 
Haylock, M., Hofstra, N., Klein Tank, A., Klok, E., Jones, P. \& New, M. (2008) A European daily high-resolution gridded dataset of surface temperature and precipitation. Journal of Geophysical Research, 113.

Huey, R.B., Carlson, M., Crozier, L., Frazier, M., Hamilton, H., Harley, C., Hoang, A. \& Kingsolver, J.G. (2002) Plants versus animals: do they deal with stress in different ways? Integrative and Comparative Biology, 42, 415-423.

IBM Corp. (2013) IBM SPSS Statistics for Windows.

Ichiishi, S., Nagamitsu, T., Kondo, Y., Iwashina, T., Kondo, K., Tagashira, N. \& Orikazu (1999) Effects of macro-components and sucrose in the medium on in vitro red-colour pigmentation in Dionea muscipula Ellis and Drosera spathulata Labill. Plant Biotechnology, 16, 235-238.

Jablonski, N.G. \& Chaplin, G. (2000) The evolution of human skin coloration. Journal of Human Evolution, 39, 57-106.

Kikvidze, Z., Michalet, R., Brooker, R.W., Cavieres, L.A., Lortie, C.J., Pugnaire, F.I. \& Callaway, R.M. (2011) Climatic drivers of plant-plant interactions and diversity in alpine communities. Alpine Botany, 121, 63-70.

KNMI (2013) KNMI Climate Explorer.

Koski, M.H. \& Ashman, T.-L. (2015) Floral pigmentation patterns provide an example of Gloger's rule in plants. Nature Plants, 1, 14007.

Lai, Y.C., Shiroishi, T., Moriwaki, K., Motokawa, M. \& Yu, H.T. (2008) Variation of coat color in house mice throughout Asia. Journal of Zoology, 274, 270-276.

Lloyd, F.E. (1942) The Carnivorous Plants, The Chronica Botanica Company.

Mendez, M., Jones, D.G. \& Manetas, Y. (1999) Enhanced UV-B radiation under field conditions increases anthocyanin and reduces the risk of photoinhibition but does not affect growth in the carnivorous plant Pinguicula vulgaris. New Phytologist, 144, 275-282.

Manetas, Y. (2006) Why some leaves are anthocyanic and why most anthocyanic leaves are red? Flora, 201, 163-177.

Millett, J., Foot, G.W. \& Svensson, B.M. (2015) Nitrogen deposition and prey nitrogen uptake control the nutrition of the carnivorous plant Drosera rotundifolia. Science of The Total Environment, 512-513, 631-636.

Millett, J., Svensson, B.M., Newton, J. \& Rydin, H. (2012) Reliance on prey-derived nitrogen by the carnivorous plant Drosera rotundifolia decreases with increasing nitrogen deposition. The New phytologist, 195, 182-8.

Millien, V., Kathleen Lyons, S., Olson, L., Smith, F. a., Wilson, A.B. \& Yom-Tov, Y. (2006) Ecotypic variation in the context of global climate change: revisiting the rules. Ecology Letters, 9, 853-869.

Mittelbach, G.G., Schemske, D.W., Cornell, H. V, Allen, A.P., Brown, J.M., Bush, M.B., Harrison, S.P., Hurlbert, A.H., Knowlton, N., Lessios, H. a, McCain, C.M., McCune, A.R., McDade, L. a, McPeek, M. a, Near, T.J., Price, T.D., Ricklefs, R.E., Roy, K., Sax, D.F., Schluter, D., Sobel, J.M. \& Turelli, M. (2007) Evolution and the latitudinal diversity gradient: speciation, extinction and biogeography. 
Moles, A. T., Warton, D. I., Warman, L., Swenson, N. G., Laffan, S. W., Zanne, A. E., Pitman, A., Hemmings, F. A. and Leishman, M. R. (2009), Global patterns in plant height. Journal of Ecology, 97, 923-932. doi:10.1111/j.13652745.2009.01526.x

NEGTAP (2001) Regional estimation of pollutant gas dry deposition in the UK: model description, sensitivity analyses and outputs, Edinburgh.

Ocean Optics (2009). Spectrasuite spectrometer operating software. Ocean Optics Inc., USA.

Pieterse, G., Bleeker, A., Vermeulen, A.T., Wu, Y. \& Erismn, J.W. (2007) High resolution modelling of atmosphere-canopy exchange of acidifying and eutrophying components and carbon dioxide for European forests. Tellus, 59B, 412-424.

Schemske, D.W., Mittelbach, G.G., Cornell, H. V., Sobel, J.M. \& Roy, K. (2009) Is there a latitudinal gradient in the importance of biotic interactions? Annual Review of Ecology, Evolution, and Systematics, 40, 245-269.

Smith, R.I., Fowler, D., Sutton, M.A., Flechard, C. \& Coyle, M. (2000) Regional estimation of pollutant gas dry deposition in the UK: model description, sensitivity analyses and outputs. Atmospheric Environment, 34, 3757-3777.

Takahashi, S. \& Badger, M.R. (2011) Photoprotection in plants: a new light on photosystem II damage. Trends in Plant Science, 16, 53-60.

Tuomaala, M., Kaitala, A. \& Rutowski, R.L. (2012) Females show greater changes in wing colour with latitude than males in the green-veined white butterfly, Pieris napi (Lepidoptera: Pieridae). Biological Journal of the Linnean Society, 107, 899-909.

Willis, K.J., Feurdean, A., Birks, H.J.B., Bjune, A.E., Breman, E., Broekman, R., Grytnes, J.-A., New, M., Singarayer, J.S. \& Rozema, J. (2011) Quantification of UV-B flux through time using UV-B-absorbing compounds contained in fossil Pinus sporopollenin. New Phytologist, 192, 553-560.

Wisz, M. S., Pottier, J., Kissling, W. D., Pellissier, L., Lenoir, J., Damgaard, C. F., Dormann, C. F., Forchhammer, M. C., Grytnes, J.-A., Guisan, A., Heikkinen, R. K., Høye, T. T., Kühn, I., Luoto, M., Maiorano, L., Nilsson, M.-C., Normand, S., Öckinger, E., Schmidt, N. M., Termansen, M., Timmermann, A., Wardle, D. A., Aastrup, P. \& Svenning, J.-C. (2013), The role of biotic interactions in shaping distributions and realised assemblages of species: implications for species distribution modelling. Biological Reviews, 88, 15-30. doi:10.1111/j.1469185X.2012.00235.X

Zeuss, D., Brandl, R., Brändle, M., Rahbek, C. \& Brunzel, S. (2014) Global warming favours light-coloured insects in Europe. Nature Communications, 5, 3874.

\section{Data accessibility}

Data are available in supplementary material.

\section{Biosketch}


630 Jonathan Millett is a senior lecturer in the Centre for Hydrological and Ecosystem

631 Sciences, in the Department of Geography in Loughborough University. His work is

632 focussed on linking plant community responses to environmental variability with plant

633 physiological responses. He works mainly on carnivorous plants, bogs, forest and

634 sand dunes. www.drjonmillett.net Author contributions: J.M and B.S. conceived the

635 ideas; J.M., G.W.F. and J.C.T. collected the data; J.M., G.W.F. and J.C.T. analysed

636 the data; and J.M. and B.S. led the writing.

637 Editor: W. Daniel Kissling

638 
641 Table 1 Results of principle components analysis of between site variability in 13 642 environmental variables for sites across north-western Europe. Presented are the 643 loadings for each variable on the first three axes.

644

\begin{tabular}{lrrr}
\hline Variable & Axis 1 & Axis 2 & Axis 3 \\
\hline Total N deposition & 0.895 & 0.235 & 0.321 \\
Total S deposition & 0.836 & 0.431 & 0.084 \\
$\mathrm{NO}_{3}$ deposition & 0.951 & 0.052 & 0.237 \\
$\mathrm{NH}_{4}$ deposition & 0.762 & 0.376 & 0.365 \\
July maximum temperature & 0.162 & 0.908 & -0.142 \\
Growing Degree Days (base 5) & 0.388 & 0.813 & 0.400 \\
Mean summer temperature & 0.292 & 0.912 & 0.127 \\
$\mathrm{NH}_{4}: \mathrm{NO}_{3}$ & -0.158 & 0.542 & 0.502 \\
UV-B & 0.368 & 0.630 & 0.132 \\
January minimum temperature & 0.349 & 0.242 & 0.887 \\
Variance in monthly temperature & -0.349 & -0.207 & -0.888 \\
Annual precipitation & 0.139 & -0.216 & 0.773 \\
Mean annual temperature & 0.403 & 0.523 & 0.727 \\
Cumulative proportion of variance explained & 0.295 & 0.593 & 0.855 \\
\hline
\end{tabular}


647 Table 2 Results of principle components analysis of between site variability in three 648 measures of vegetation influence, and Drosera rotundifolia leaf colour

649 characteristics, for plants growing on bogs in north-western Europe. Presented are 650 the loadings for each variable on the first axes.

651

652

\begin{tabular}{lrrr}
\hline Vegetation influence & \multicolumn{2}{l}{ Leaf colour } \\
\hline Variable & Axis 1 & Variable & Axis 1 \\
\hline Vegetation cover & 0.870 & CIE LAB a* & 0.996 \\
Vegetation height & 0.949 & Dominant wavelength & 0.991 \\
\% light transmitted through canopy & -0.960 & Red:green & 0.974 \\
& & Red & 0.774 \\
& & Green & -0.853
\end{tabular}

$\%$ of variance explained

85.97

85.01 
Table 3 Results of stepwise regression for relationship between Drosera rotundifolia leaf colour, vegetation characteristics and environmental variation with geographic location, and between leaf colour and vegetation characteristics with environmental variation, for sites across north-western

658 Europe.

\begin{tabular}{|c|c|c|c|c|c|}
\hline Dependent variable & Stepwise selected independent variables & $r^{2}$ & Adjusted $r^{2}$ & $\boldsymbol{F}$ & $\boldsymbol{P}$ \\
\hline & Geographic variables & & & & \\
\hline Leaf colour & Latitude, longitude & 0.686 & 0.657 & 23.976 & $<0.001$ \\
\hline Canopy influence & Latitude & 0.816 & 0.806 & 75.583 & $<0.001$ \\
\hline Vegetation height & Latitude & 0.847 & 0.838 & 94.346 & $<0.001$ \\
\hline Abiotic PCA axis 1 & Latitude & 0.291 & 0.262 & 9.873 & 0.004 \\
\hline Abiotic PCA axis 2 & Latitude, Longitude & 0.551 & 0.512 & 14.126 & $<0.001$ \\
\hline \multirow[t]{2}{*}{ Abiotic PCA axis 3} & Longitude & 0.749 & 0.738 & 71.472 & $<0.001$ \\
\hline & Abiotic variables & & & & \\
\hline Leaf colour & PCA Axis $1 \& 3$ & 0.744 & 0.721 & 32.008 & $<0.001$ \\
\hline Canopy influence & PCA axis $3,1,2$ & 0.865 & 0.838 & 32.116 & $<0.001$ \\
\hline Vegetation Height & PCA axis $3,1,2$ & 0.895 & 0.874 & 42.486 & $<0.001$ \\
\hline
\end{tabular}

659

660

661

662

663

664

665

666 


\section{Figure 1}

669 Location of study sites (site details in Table S1). The colour of the markers is indicative of the average colour of the leaves of Drosera rotundifolia growing on Sphagnum hummocks. The white marker at site UK10 is because no $D$. rotundifolia were present. The markers for SW1, 2 \& 3 are offset to make them visible.

\section{Figure 2}

Geographic variation in vascular plant canopy influence and Drosera rotundifolia leaf colour, for plants growing across north-western Europe. Presented are the mean site values (circles) for variation with longitude ( $a$ and $b$ ) or latitude (c and d) in the axis 1 scores from a principle components analysis (PCA) of measures of canopy influence ( $(\mathrm{a}$ and $\mathrm{b}$ ) and $D$. rotundifolia leaf colour (c and d), with the fitted regression line (where statistically significant). The simple linear regression model is shown in b; c and $d$ are partial regression plots where the axes and regression line are adjusted (corrected) to remove variability due to the other variables included in the full multiple regression model, to allow the bivariate relationship to be visualised. Individual leaf colour and vegetation influence measures are shown in table 2.

\section{Figure 3}

Geographic variation in the abiotic environment on bogs in north-weestern Europe. Presented are the mean site values (circles) for variation with longitude ( $a$ and $b$ ) or latitude ( $c$ and $d$ ) in the first three axes from a principle components analysis (PCA) of environmental variables, with the fitted regression line. The simple linear regression model is shown in a and $c$; $b$ and $d$ are partial regression plots where the axes and regression line are adjusted (corrected) to remove variability due to the other variables included in the full multiple regression model, to allow the bivariate relationship to be visualised. Individual environmental measures are shown in table 1.

\section{Figure 4}

Relationship between the abiotic environment on bogs in north-western Europe and vascular plant canopy influence and Drosera rotundifolia leaf colour. Presented are the mean site values (circles) for variation in the axis 1 scores from a principle components analysis (PCA) of measures of canopy influence (a, c, and e) or leaf colour ( $b$ and $d)$, and variation in the first three axes from a principle components analysis (PCA) of environmental variables. All graphs are partial regression plots, where the axes and regression line are adjusted (corrected) to remove variability due to the other variables included in the full multiple regression model, to allow the bivariate relationship to be visualised. Individual environmental, leaf colour and vegetation influence measures are shown in tables 1 and 2 . 


\section{Figure 5}

706 The relationship between canopy influence and Drosera rotundifolia leaf colour on

707 bogs across north-western Europe. Presented are the values (circles) for the axis 1

708 scores from a principle components analysis (PCA) of measures of canopy influence

709 and leaf colour for individual plots within bogs. The lines represent the fitted

710 regression line for the plots on each bog, based on a multi-level linear mixed model

711 analysis. The equation for each line is presented in appendix S7, site codes are

712 explained in appendix S1. Individual leaf colour and vegetation influence measures

713 are shown in table 2.

\section{$714 \quad$ Figure 6}

715 The impact of vegetation removal and vegetation removal plus shade addition

716 treatments on canopy light transmission and Drosera rotundifolia leaf colour at the

717 Humberhead Peatlands. Presented are the mean ( \pm se) for measurements of three

718 different treatments: no vegetation removal ('natural'), all above-ground vegetation

719 removed ('removed'), all above-ground vegetation removed and shade cloth added

720 ('removed+shaded'). Treatments that are significantly different from each other $(\mathrm{P}<$

7210.05 , based on Fisher's LSD) are indicated by different letters. Leaf/trap colour is

722 presented in CIE $1976\left(L^{*} a * b *\right)$ colour space (CIE LAB), where $a^{*}$ represents a

723 green - red axis of colour. Positive values represent red colours while negative

724 values represent green colours. 
Figure 1

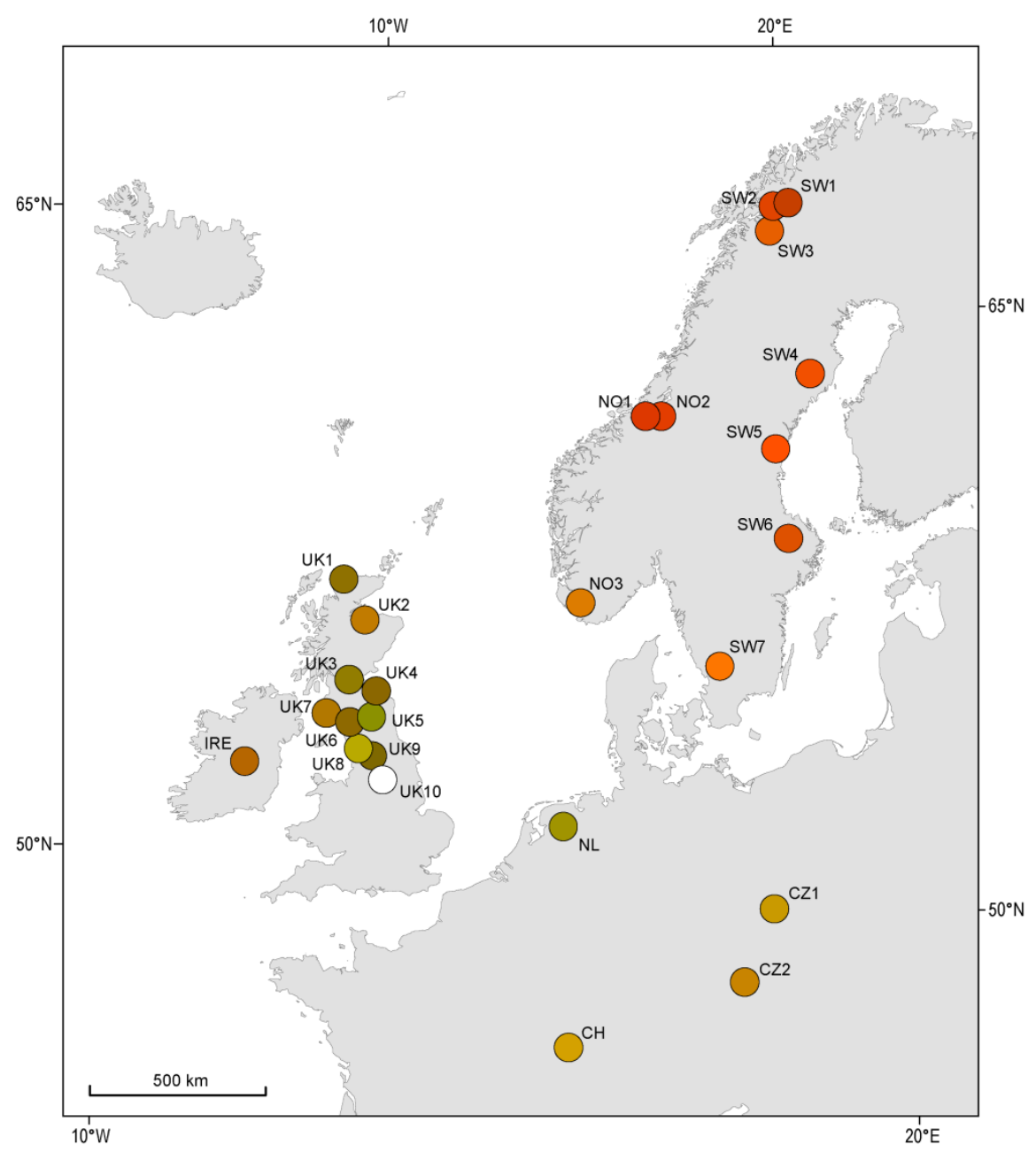




\section{Figure 2}

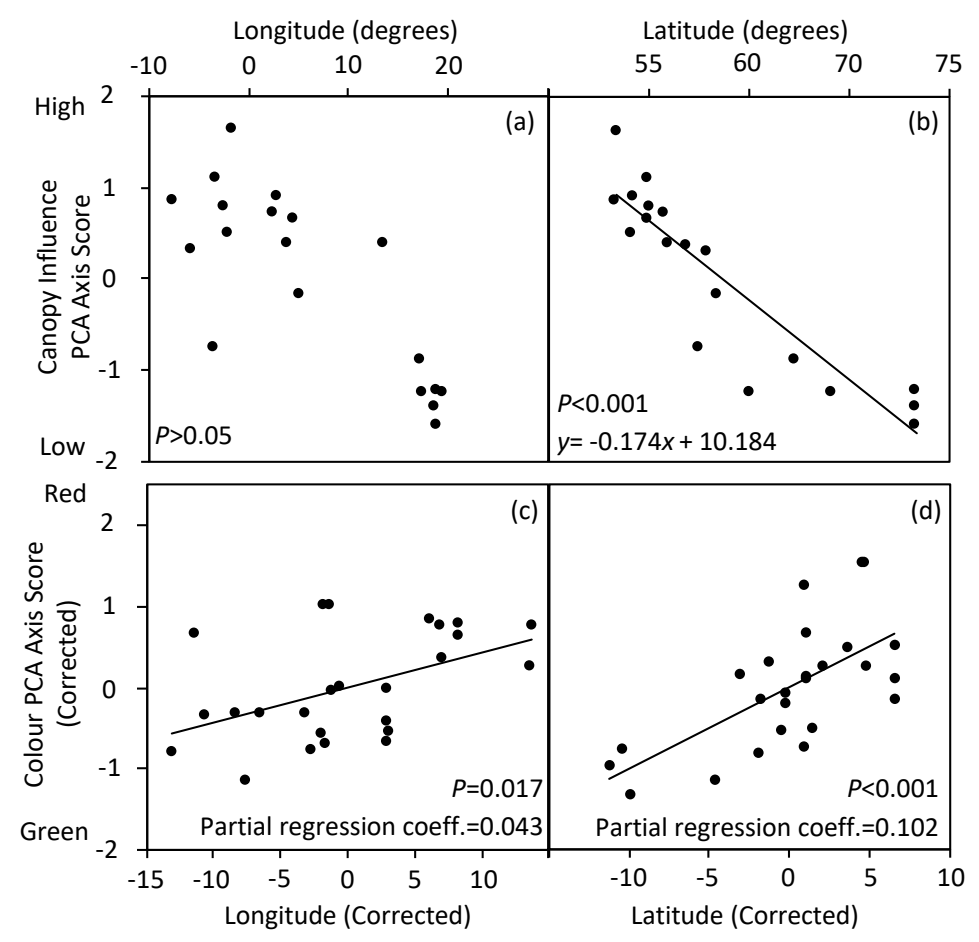




\section{Figure 3}

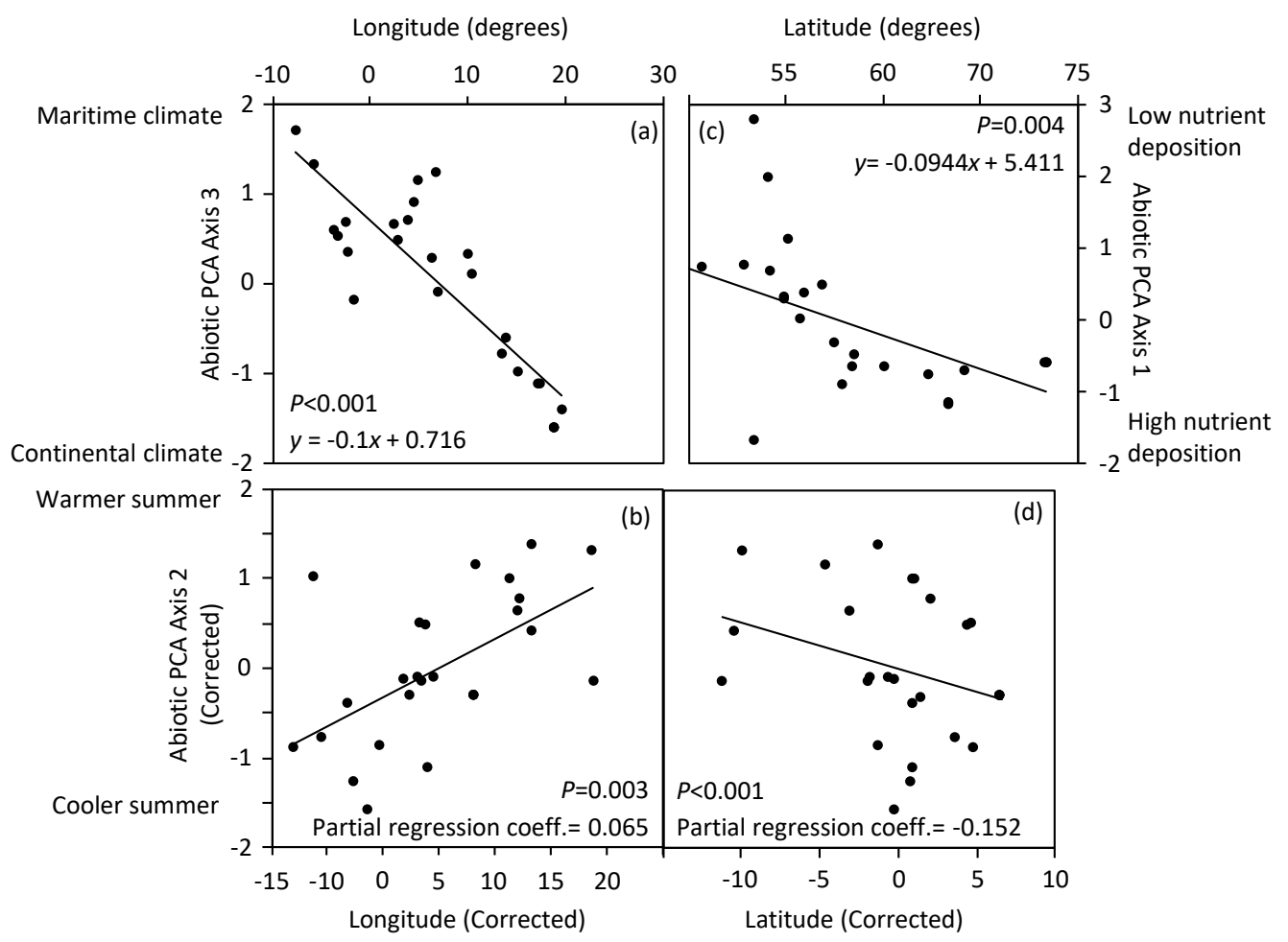




\section{Figure 4}

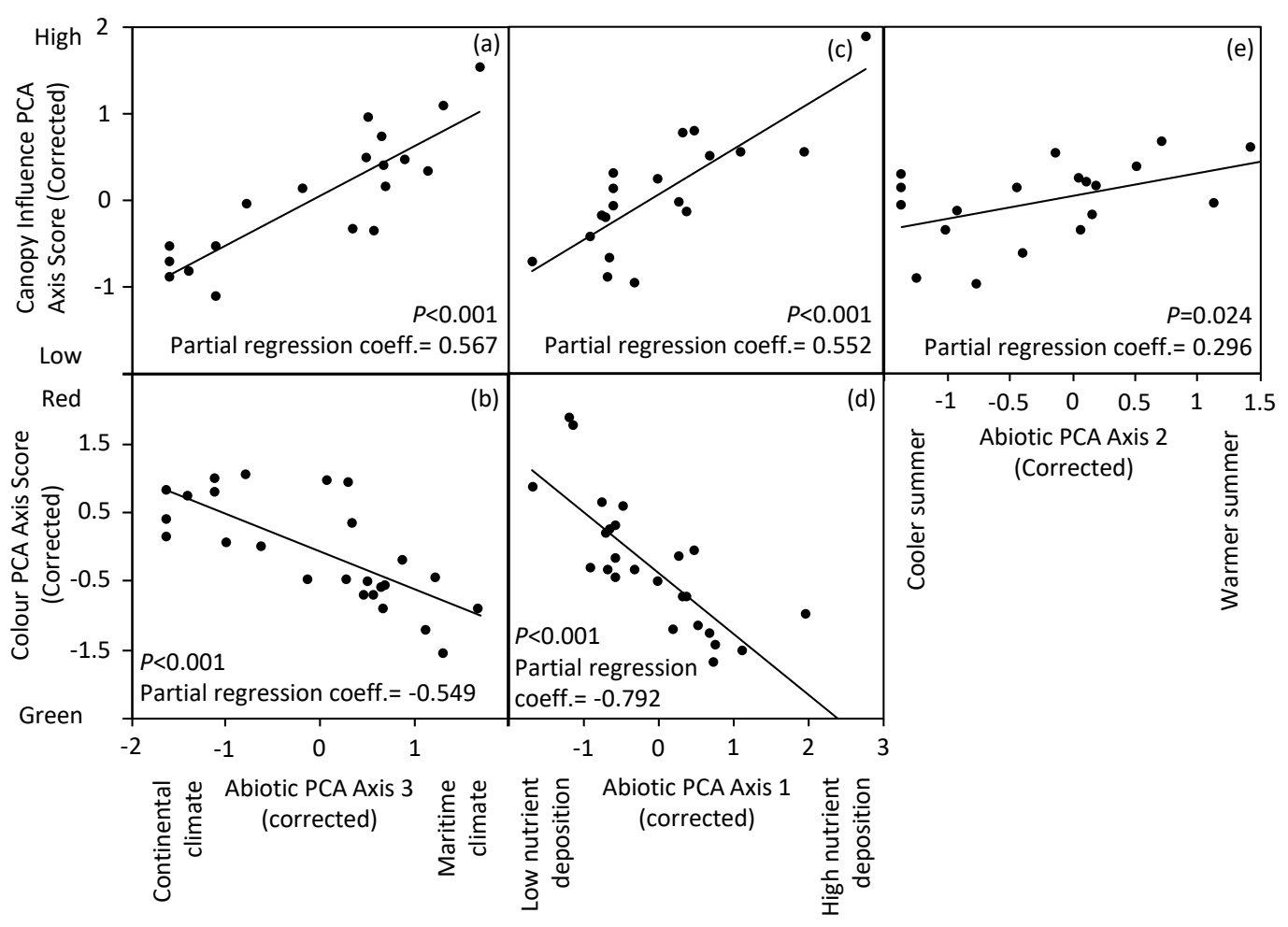




\section{Figure 5}

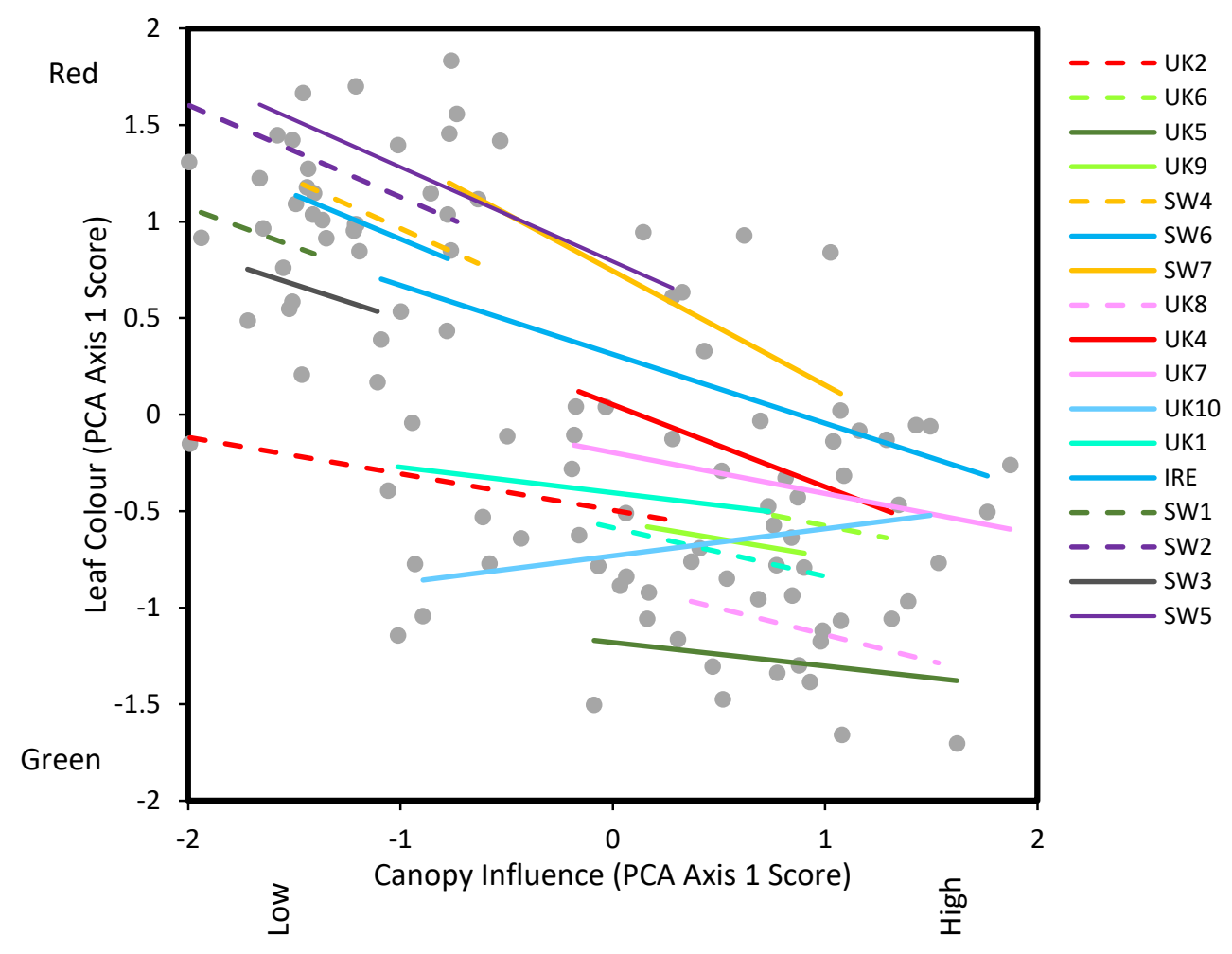




\section{Figure 6}

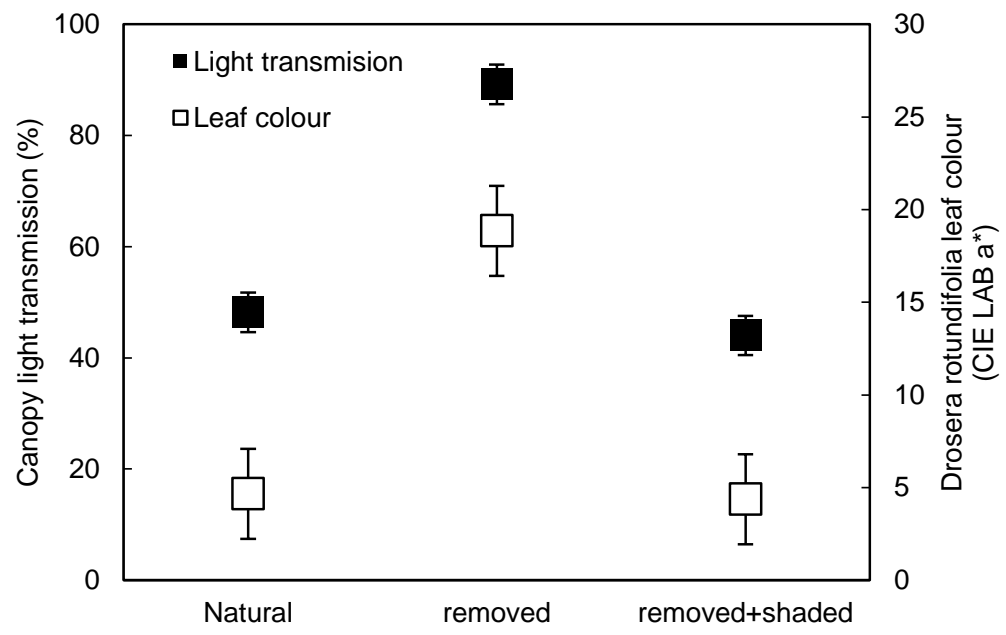


Geographic variation in Sundew (Drosera) leaf colour: plant-plant interactions counteract expected effects of abiotic factors. 
Appendix S1 Characteristics of study sites.

Table S1.1 Characteristics of study sites.

\begin{tabular}{|c|c|c|c|c|c|c|c|c|c|c|}
\hline Site & Name & $\begin{array}{l}\text { Longitude } \\
\left({ }^{\circ} \mathrm{E}\right)\end{array}$ & $\begin{array}{l}\text { Latitude } \\
\left({ }^{\circ} \mathrm{N}\right)\end{array}$ & $\begin{array}{l}\text { Measurement } \\
\text { date }\end{array}$ & $\begin{array}{l}\text { Total } \\
\text { atmospheric } \\
\text { S deposition } \\
\left(\mathrm{mg} \mathrm{m}^{-2} \mathrm{yr}^{-1}\right)\end{array}$ & $\begin{array}{l}\text { Total } \\
\text { atmospheric } \\
\mathrm{NO}_{3} \text { deposition } \\
\left(\mathrm{mg} \mathrm{m}^{-2} \mathrm{yr}^{-1}\right)\end{array}$ & $\begin{array}{l}\text { Total } \\
\text { atmospheric } \\
\mathrm{NH}_{4} \\
\text { deposition (mg } \\
\mathrm{m}^{-2} \mathrm{yr}^{-1} \text { ) }\end{array}$ & $\begin{array}{l}\text { Total } \\
\text { atmospheric } \\
\mathrm{N} \\
\text { deposition } \\
\left(\mathrm{mg} \mathrm{m}^{-2} \mathrm{yr}^{-}\right. \\
\left.{ }^{1}\right)\end{array}$ & $\begin{array}{l}\text { Mean annual } \\
\text { precipitation } \\
(\mathrm{mm}) *\end{array}$ & $\begin{array}{l}\text { Mean } \\
\text { annual } \\
\text { temp. } \\
\left({ }^{\circ} \mathrm{C}\right)^{\star}\end{array}$ \\
\hline SW1 & Abisko 1 & 18.810 & 68.355 & 20.07 .2013 & 0.030 & 0.030 & 0.014 & 0.044 & 517 & -0.86 \\
\hline sw2 & Abisko 2 & 18.797 & 68.355 & 23.07 .2013 & 0.030 & 0.030 & 0.014 & 0.044 & 517 & -0.86 \\
\hline sw3 & Abisko 3 & 18.778 & 68.341 & 25.07 .2013 & 0.030 & 0.030 & 0.014 & 0.044 & 517 & -0.86 \\
\hline SW4 & Lappmyran & 19.583 & 64.164 & 17.08 .2013 & 0.114 & 0.138 & 0.082 & 0.220 & 634 & 2.37 \\
\hline NO1 & Skjetnmyra & 9.962 & 63.319 & $20 / 21.08 .2011$ & 0.069 & 0.092 & 0.090 & 0.182 & 1135 & 6.07 \\
\hline NO2 & Lysklett-Myran & 10.493 & 63.315 & 17/18.08.2011 & 0.069 & 0.092 & 0.090 & 0.182 & 1065 & 5.16 \\
\hline SW5 & Sundsvall & 17.156 & 62.326 & 19.08 .2013 & 0.137 & 0.163 & 0.101 & 0.264 & 659 & 4.00 \\
\hline SW6 & Åkerlänna Römossen & 17.354 & 60.016 & 21.08 .2013 & 0.183 & 0.262 & 0.174 & 0.436 & 630 & 5.54 \\
\hline NO3 & Bervamyra & 6.748 & 58.519 & 23/24.08.2011 & 0.239 & 0.300 & 0.191 & 0.492 & 2269 & 5.59 \\
\hline UK1 & Laxford Bridge & 5.017 & 58.371 & 06.08 .2013 & 0.121 & 0.302 & 0.334 & 0.637 & 1118 & 8.15 \\
\hline UK2 & Moidach More & -3.614 & 57.457 & 9/10.08.2012 & 0.153 & 0.407 & 0.352 & 0.759 & 905 & 7.13 \\
\hline SW7 & Saxnäs Mosse & 13.508 & 56.904 & 23.08.2013 & 0.522 & 0.631 & 0.555 & 1.186 & 878 & 6.40 \\
\hline UK3 & Black Loch Moss & 3.835 & 55.904 & 03.08 .2013 & 0.381 & 0.630 & 0.823 & 1.453 & 1291 & 8.37 \\
\hline UK4 & Dogden Moss & 2.504 & 55.740 & 01.08 .2013 & 0.228 & 0.534 & 0.702 & 1.237 & 1039 & 8.11 \\
\hline UK5 & Butterburn Flow & -2.507 & 55.072 & 23/24.08.2012 & 0.258 & 1.078 & 0.919 & 1.997 & 1474 & 7.45 \\
\hline UK6 & Bowness Common & -3.265 & 54.923 & 31.07 .2013 & 0.373 & 0.678 & 0.498 & 1.176 & 1158 & 8.49 \\
\hline UK7 & Caresgowan Moss & 4.455 & 54.899 & 08.08 .2013 & 0.316 & 0.642 & 0.830 & 1.472 & 1418 & 8.8 \\
\hline UK8 & Meathop Moss & 2.856 & 54.228 & 30.07 .2013 & 0.428 & 0.729 & 0.901 & 1.629 & 1093 & 9.65 \\
\hline UK9 & Malham Tarn & -2.175 & 54.097 & 29.07 .2013 & 0.502 & 1.319 & 1.094 & 2.413 & 1310 & 7.25 \\
\hline UK10 & Ringinglow Bog & -1.597 & 53.348 & 20/21.08.2012 & 0.943 & 1.493 & 1.271 & 2.764 & 956 & 8.86 \\
\hline IRE & Clara Bog & -7.638 & 53.322 & 09.08 .2013 & 0.207 & 0.157 & 0.716 & 0.873 & 975 & 9.23 \\
\hline $\mathrm{NL}$ & t Groot Veen & 6.448 & 52.834 & 20/21.07.2011 & 0.619 & 0.611 & 1.635 & 2.246 & 876 & 10.02 \\
\hline CZ1 & Chiadla & 15.249 & 50.680 & 7/8.08.2011 & 0.762 & 0.667 & 0.671 & 1.338 & 749 & 8.82 \\
\hline CZ2 & Mrtvy' luh & 13.878 & 48.870 & 10/11.08.2011 & 0.442 & 0.617 & 0.681 & 1.298 & 963 & 6.65 \\
\hline $\mathrm{CH}$ & Etang de la Gruere & 7.043 & 47.239 & $26 / 28.07 .2011$ & 0.381 & 0.545 & 0.806 & 1.351 & 1105 & 8.3 \\
\hline
\end{tabular}


*Mean annual (JUL-JUN) precipitation and temperature for the 5 years before sampling 
$1 \quad$ Appendix S2 Leaf colour measurement methods

2 Leaf reflectance was measured using an Ocean Optics USB4000 VIS-NIR miniature spectrometer. This 3 spectrometer measures reflectance in the range 350-1000 nm in steps of $25 \mu \mathrm{m}$. Because plant 4 pigments degrade over time, we measured colour in the field. We therefore used the sun as the light 5 source and adjusted using a Kodak white balance card (90\% reflectance). We held the sensor $2 \mathrm{~cm}$ 6 from the leaf surface, data were captured using the Ocean optics SpectraSuite software. One single 7 measure of reflectance was used for each leaf based on the mean of 20 measurements. Data were 8 smoothed using a boxcar width of 20 data points. Once captured we calculated colour measures 9 using the SpectraSuite software assuming a D75 illuminant and a 2 degree observer. We calculated 10 the location of the colour of the leaf in CIE $1976\left(L^{*} a^{*} b^{*}\right)$ colour space (CIELAB). This standard colour 11 space includes all colours perceivable to humans. Each colour is defined by its position in the colour 12 space based on the 'Lightness' ( $\left.L^{*}\right)$ of a colour, its position between red and green ( $a^{*}$, negative $=$ 13 green, positive $=$ red) and its position between blue and yellow ( $b^{*}$, negative-blue, positive = yellow). 14 Thus CIELAB enables assessment of colour difference and how red or green an object is by the value 15 of the $a^{*}$ axis. We also used the Dominant Wavelength form the SpectraSuite analysis. This is the 16 dominant wavelength of the colour in CIE 1976 colourspace, removing differences in saturation or 17 intensity. It is calculated $\mathrm{b}$ We used the reflectance spectrum to calculate mean red reflectance 18 (average reflectance in the range: 600-699 $\mathrm{nm}$ ) and mean green reflectance (average reflectance in 19 the range 500-599 $\mathrm{nm}$ ). We then used these values to calculate the ratio of red:green reflectance. 
Appendix S3 Results of stepwise multiple regression.

Table S3.2 Results of stepwise multiple regression analysis of geographical variation in a. Drosera rotundifolia leaf colour, b. canopy influence of vascular plant vegetation in which the $D$. rotundifolia are growing, and c. the height of vascular plant vegetation in which the $D$. rotundifolia are growing.

a. Drosera rotundifolia Leaf colour.

\begin{tabular}{|c|c|c|c|c|c|c|}
\hline \multirow{3}{*}{ Variable } & \multicolumn{3}{|c|}{ Model 1} & \multicolumn{3}{|c|}{ Model 2} \\
\hline & $B$ & SE B & $B$ & $B$ & $S E B$ & 8 \\
\hline & & & & & & $P$ \\
\hline Constant & $-7.759 * * *$ & 1.365 & & $-6.151 * * *$ & 1.371 & \\
\hline Latitude & $0.135 * * *$ & 0.023 & 0.768 & $0.102 * * *$ & 0.025 & 0.578 \\
\hline Longitude & & & & $0.043^{*}$ & 0.017 & 0.363 \\
\hline & & 0.590 & & & 0.686 & \\
\hline$F$ for change in $R^{2}$ & & $33.098 * * *$ & & & $6.680^{*}$ & \\
\hline
\end{tabular}

$* P<0.005, * * * P<0.001$

b. Canopy influence

\begin{tabular}{llll}
\hline & \multicolumn{3}{c}{ Model 1 } \\
\cline { 2 - 4 } Variable & $B$ & SE B & 6 \\
\hline Constant & $10.814^{* * *}$ & 1.176 \\
Latitude & $-0.174^{* * *}$ & 0.020 & -0.904 \\
Longitudet & -0.146 & & \\
$\mathrm{R}^{2}$ & \multicolumn{3}{c}{0.816} \\
$\mathrm{~F}_{\text {for change in } \mathrm{R}^{2}}$ & \multicolumn{3}{c}{$75.583^{* * *}$} \\
\hline Texcluded from model, $* * * P<0.001$
\end{tabular}

\section{c. Vegetation height}

\begin{tabular}{llll}
\hline & \multicolumn{3}{c}{ Model 1 } \\
\cline { 2 - 4 } Variable & $B$ & SE B & B \\
\hline Constant & $91.779 * * *$ & 7.922 & \\
Latitude & $-1.308^{* * *}$ & 0.135 & -0.921 \\
Longitude & 0.004 & & \\
$\mathrm{R}^{2}$ & 0.847 & & \\
$\mathrm{~F}$ for change in $\mathrm{R}^{2}$ & $94.346 * * *$ \\
$* * * P<0.001$ & &
\end{tabular}


Table S3.3 Results of stepwise multiple regression analysis of geographic variation in principle component axis scores from principle components analysis of abiotic conditions at each site. a. Axis 1 , which reflects nutrient deposition differences among the sites, with high scores on this axis representing sites with a high $\mathrm{N}$ and $\mathrm{S}$ deposition load (higher total N, total S, NO3 and NH4 deposition); b. axis 2 which reflects differences among sites in summer meteorological conditions, sites with high scores on this axis had warmer summers and a longer growing season (higher mean summer temperature, high maximum July temperature and high GDD); c. axis 3 which reflects the continentality of the climate, sites with high scores on this axis had a more maritime, less continental climate (high January minimum temperature, mean annual temperature, and precipitation, and low monthly temperature variance).

\section{a. Abiotic PCA axis 1}

\begin{tabular}{llll}
\hline & \multicolumn{3}{c}{ Model 1 } \\
\cline { 2 - 4 } Variable & $B$ & SE B & 6 \\
\hline Constant & 5.41 & 1.730 & \\
Latitude & $-0.094^{* *}$ & 0.030 & -0.540 \\
longitude & & & \\
$\mathrm{R}^{2}$ & & 0.291 & \\
$\mathrm{~F}$ for change in $\mathrm{R}^{2}$ & & $9.873^{* *}$ & \\
\hline
\end{tabular}

\section{b. Abiotic PCA axis 2}

\begin{tabular}{lllllll} 
& \multicolumn{3}{c}{ Model 1 } & & \multicolumn{3}{c}{ Model 2 } \\
\cline { 2 - 7 } Variable & $B$ & SE B & 6 & $B$ & SE B & 6 \\
\hline Constant & 5.760 & 1.682 & & 8.300 & 1.596 & \\
Latitude & $-0.100^{* *}$ & 0.029 & -0.575 & $-0.152^{* * *}$ & 0.029 & -0.874 \\
longitude & & & & $0.065^{* *}$ & 0.019 & 0.557 \\
$\mathrm{R}^{2}$ & & 0.330 & & & 0.551 & \\
$\mathrm{~F}^{2}$ for change in $\mathrm{R}^{2}$ & & $11.839^{* *}$ & & & $11.321^{* *}$ & \\
\hline
\end{tabular}

$40 \quad{ }^{* *} P<0.001,{ }^{* * *} P<0.001$

41 c. Abiotic PCA axis 3

\begin{tabular}{llll}
\hline & \multicolumn{3}{c}{ Model 1 } \\
\cline { 2 - 4 } Variable & $B$ & $S E B$ & 6 \\
\hline Constant & 0.716 & 0.131 & \\
Latitude & $-0.100^{* * *}$ & 0.012 & -0.865 \\
longitude & & & \\
$\mathrm{R}^{2}$ & & & \\
$\mathrm{~F}$ for change in $\mathrm{R}^{2}$ & & 0.749 & \\
\hline$* * * P<0.001$ & & $71.472^{* * *}$ &
\end{tabular}


Table S3.4 Results of stepwise multiple regression analysis of relationship between environmental variation and a. Drosera rotundifolia leaf colour, b. canopy influence of vascular plant vegetation in which the $D$. rotundifolia are growing, and c. the height of vascular plant vegetation in which the $D$. rotundifolia are growing. Axis 1,2 and 3 are principle component axis scores from principle components analysis of abiotic conditions at each site. Axis 1 reflects nutrient deposition differences among the sites, with high scores on this axis representing sites with a high $\mathrm{N}$ and $\mathrm{S}$ deposition load (higher total N, total S, NO3 and NH4 deposition); axis 2 reflects differences among sites in summer meteorological conditions, sites with high scores on this axis had warmer summers and a longer growing season (higher mean summer temperature, high maximum July temperature and high GDD); axis 3 reflects the continentality of the climate, sites with high scores on this axis had a more maritime, less continental climate (high January minimum temperature, mean annual temperature, and precipitation, and low monthly temperature variance).

\section{1 a. Drosera rotundifolia leaf colour}

\begin{tabular}{lllllll}
\hline & \multicolumn{3}{c}{ Model 1 } & \multicolumn{3}{c}{ Model 2 } \\
\cline { 2 - 6 } Variable & $B$ & SE B & $B$ & $B$ & SE B & 6 \\
\hline Constant & -0.036 & 0.157 & & -0.030 & 0.109 & \\
Axis 1 & $-0.809 * * *$ & 0.189 & -0.666 & $-0.792^{* * *}$ & 0.131 & -0.653 \\
Axis 2 & & & & & & \\
Axis 3 & & & $-0.549 * * *$ & 0.108 & -0.548 \\
$\mathrm{R}^{2}$ & & 0.444 & & 0.744 & \\
$\mathrm{~F}_{\text {for change in } \mathrm{R}^{2}}$ & $18.352^{* * *}$ & & & $25.843^{* * *}$ & \\
\hline
\end{tabular}

52 texcluded from model, $* * * P<0.001$

53 b. Canopy influence

\begin{tabular}{|c|c|c|c|c|c|c|c|c|c|}
\hline \multirow[b]{2}{*}{ Variable } & \multicolumn{3}{|c|}{ Model 1} & \multicolumn{3}{|c|}{ Model 2} & \multicolumn{3}{|c|}{ Model 3} \\
\hline & $B$ & $S E B$ & b & $B$ & $S E B$ & b & $B$ & $S E B$ & b \\
\hline Constant & 0.010 & 0.161 & & -0.006 & 0.106 & & 0.061 & 0.096 & \\
\hline Axis 1 & & & & $0.490 * * *$ & 0.103 & 0.524 & $0.296^{*}$ & 0.118 & 0.252 \\
\hline Axis 2 & & & & $0.620 * * *$ & 0.099 & 0.685 & $0.552 * * *$ & 0.089 & 0.591 \\
\hline Axis 3 & $0.664 * * *$ & 0.150 & 0.732 & & & & $0.567 * * *$ & 0.089 & 0.626 \\
\hline $\mathrm{R}^{2}$ & & 0.536 & & & 0.809 & & & 0.865 & \\
\hline$F$ for change in $R^{2}$ & & $19.67 €$ & & & 22.810 & & & $6.278^{*}$ & \\
\hline
\end{tabular}


c. Vegetation height

\begin{tabular}{|c|c|c|c|c|c|c|c|c|c|}
\hline \multirow[b]{2}{*}{ Variable } & \multicolumn{3}{|c|}{ Model 1} & \multicolumn{3}{|c|}{ Model 2} & \multicolumn{3}{|c|}{ Model 3} \\
\hline & $B$ & $S E B$ & 8 & $B$ & $S E B$ & 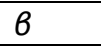 & $B$ & $S E B$ & 8 \\
\hline Constant & $15.189 * * *$ & 1.071 & & $15.097 * * *$ & 0.830 & & $15.784 * * *$ & 0.628 & \\
\hline Axis 1 & $5.286 * * *$ & 0.997 & 0.789 & $5.036 * * *$ & 0.775 & 0.752 & $4.493 * * *$ & 0.580 & 0.671 \\
\hline Axis 2 & & & & $2.811^{* *}$ & 0.799 & 0.407 & $3.446 * * *$ & 0.603 & 0.499 \\
\hline Axis 3 & & & & & & & $3.017 * *$ & 0.771 & 0.348 \\
\hline $\mathrm{R}^{2}$ & & 0.623 & & & 0.787 & & & 0.895 & \\
\hline $\mathrm{F}$ for change in $\mathrm{R}^{2}$ & & 28.08 & & & 12.368 & & & 15.30 & \\
\hline
\end{tabular}

$* * P<0.01, * * * P<0.001$

58

59 
Appendix S4 Linear mixed model results

61 Table S4.5 Characteristics of Linear Mixed Models for the relationship between vascular vegetation canopy influence and Drosera rotundifolia leaf colour. Presented are 62 characteristics for four models in ranked order based on -2log likelihood.

63

\begin{tabular}{|c|c|c|c|c|c|}
\hline $\begin{array}{l}\text { Model } \\
\text { ranking }\end{array}$ & Model & Included parameters & -2log likelihood & $\begin{array}{l}\text {-2log likelihood } \\
\text { (difference from } \\
\text { next ranked model) }\end{array}$ & $\begin{array}{l}P \text {-vale for comparison } \\
\text { with next ranked model }\end{array}$ \\
\hline
\end{tabular}

\begin{tabular}{|c|c|c|c|c|c|}
\hline 1 & $\begin{array}{l}\text { Random slopes } \\
\text { and intercepts }\end{array}$ & Site, intercept, slope & 192.647 & 0 & $<0.05$ \\
\hline 2 & Random intercepts & Site, intercept. & 201.407 & 8.76 & $<0.001$ \\
\hline 3 & Null multi-level & Site & 361.475 & 160.068 & $<0.001$ \\
\hline 4 & Null single-level & None & 560.897 & 229.422 & $<0.001$ \\
\hline
\end{tabular}




\begin{tabular}{ll}
\hline site & Fitted regression equatioß1 \\
\hline UK10 & $y=0.1394 x-0.7313$ \\
UK5 & $y=-0.122 x-1.1802$ \\
UK1 & $y=-0.1331 x-0.4048$ \\
UK9 & $y=-0.1852 x-0.5511$ \\
UK2 & $y=-0.189 x-0.4951$ \\
UK7 & $y=-0.2123 x-0.1967$ \\
UK8 & $y=-0.2733 x-0.8668$ \\
IRE & $y=-0.357 x+0.3118$ \\
SW3 & $y=-0.3591 x+0.1357$ \\
SW1 & $y=-0.4062 x+0.2608$ \\
UK4 & $y=-0.4265 x+0.052$ \\
SW6 & $y=-0.4598 x+0.4499$ \\
SW2 & $y=-0.4755 x+0.6513$ \\
SW5 & $y=-0.4889 x+0.7929$ \\
SW4 & $y=-0.4955 x+0.4686$ \\
SW7 & $y=-0.5921 x+0.7443$ \\
\hline
\end{tabular}

Table S4.6 Equations of fitted regression lines for the relationship between valcular plant canopy influence $(x)$ and Droserea rotundifolia leaf colour $(y)$ for each of 16 site around Europe. Fitted lines are derived from a multi-level Linear Mixed Model analysis. Site codes are in table S1. 